\title{
Parameterisasi Kendali PID pada Konverter DC/DC Penurun Tegangan dengan Kriteria Domain Waktu dan Efisiensi Daya
}

\author{
Andy Lukman Affandy*1, Faizal Arya Samman ${ }^{1}$, Rhiza S. Sadjad ${ }^{1}$ \\ ${ }^{1}$ Teknik Elektro, Fakultas Teknik, Universitas Hasanuddin Makassar \\ J1. Perintis Kemerdekaan Km. 10, Tamalanrea Indah, Makassar \\ *Email: luckyxco@gmail.com
}

DOI: 10.25042/jpe.052017.13

\begin{abstract}
Abstrak
Paper ini menampilkan pemodelan, rancangan dan hasil simulasi rangkaian konverter DC/DC tipe penurun tegangan, dengan pecobaan kendali menggunakan kontroler P, PI, dan PD terkompensasi. Sistem dirancang untuk tujuan penyediaan saluran DC di rumah-rumah modern masa depan yang dilengkapi dengan saluran DC selain saluran AC. Hasil rancangan menunjukkan kendali P, PI, dan PD yang digunakan untuk mempertahankan tegangan luaran DC dari converter telah memberikan kinerja yang cukup baik. Walaupun antara menggunakan kendali P, PI, dan PD tidak memiliki perbedaan yang sangat signifikan terhadap pengendalian pada beban RL dan RC. Penggunaan penggabungan kendali PI dan PD terlihat mampu meningkatkan nilai Efisiensi Daya yang disalurkan dari pada hanya menggunakan kendali P saja. Nilai Efisiensi yang didapatkan PI yaitu 84.72 dan PD yaitu 84.616. Sedangkan dengan hanya menggunakan kendali P nilai efisinsi terbaik yang didapatkan yaitu 84.283. Nilai-nilai parameter pengendali yang diperoleh antara lain $\mathrm{KP}=8191, \mathrm{KI}=63$, dan $\mathrm{KD}=7 \times 10^{-6}$. Secara umum perubahan parameter KP dan KI tidak begitu memberikan perubahan kinerja yang signifikan. Sedangkan nilai KD mesti ditentukan secara hati-hati agar dapat memberikan kinerja yang lebih baik. Kontroler PID juga secara umum masih mampu mengendalikan level tegangan DC pada batas yang dapat diterima pada pengujian dengan berbagai nilai beban resistive.
\end{abstract}

\begin{abstract}
PID Control Parameterisation on Voltage Regulator DC/DC Converter with Time Domain and Power Efficiency Criteria. This paper presents modeling, concepts and simulation DC/DC buck converter, using P, PI, and PD compensated controllers. Operating system for the purpose of providing DC in future modern homes equipped with DC channels other than AC channels. The result of P, PI, and PD control commands used to maintain the DC output of the converter has performed well. The equations between using P, PI, and PD controls do not have a very significant difference to controls in RL and RC. The use of PI and PD coupling controls is seen to increase the carrying capacity of power supplied rather than using only P controls. Efficiency value obtained by PI is 84.72 and PD is 84.616 . Using only the best P efficient control is 84,283 . Other parameter parameters are $\mathrm{KP}=8191, \mathrm{KI}=63$, and $\mathrm{KD}=7 \times 10^{-6}$. Generally, the change of $\mathrm{KP}$ and $\mathrm{KI}$ parameters does not give significant performance change. While KD must be determined carefully in order to provide better performance. PID controllers are also generally still capable of voltage levels. At various acceptable tests with various resistive values.
\end{abstract}

Kata-kunci: Energi terbarukan, Konverter DC/DC, Kontroler PID.

\section{Pendahuluan}

Energi merupakan kebutuhan dasar manusia, yang terus meningkat sejalan dengan tingkat kehidupannya. Bahan bakar minyak/energi fosil merupakan salah satu sumber energi yang bersifat tak terbarukan (non renewable energy sources) yang selama ini merupakan andalan untuk memenuhi kebutuhan energi di seluruh sektor kegiatan.

Perhatian dunia terhadap pembangunan energi terbarukan semakin meningkat. Tahun-tahun belakangan ini, misalnya, lebih dari $40 \%$ dari seluruh penambahan kapasitas pembangkit listrik di dunia dilakukan untuk memanfaatkan energi terbarukan. Hal ini semakin membuktikan bahwa energi terbarukan merupakan solusi dengan biaya yang efektif untuk memenuhi kebutuhan energi dunia.

Salah satu energi terbarukan adalah energi surya yang mencakup penggunaannya dalam pembangkit listrik. Namum pembangkit ini memiliki tegangan keluaran yang tidak tetap. Hal ini disebabkan radiasi matahari dan suhu yang 
dirasakan oleh panel surya untuk setiap waktu. Sementara alat elektronik membutuhkan tegangan yang tetap pada level tertentu.

Disisi lain penggunaannya pada konsumen tidaklah selalu sama, sehingga peyaluran daya dari pembangkit ke beban juga berubah-ubah. Dan juga kebutuhan tegangan pada perangkat elektronik juga berbeda-beda. Sebagai contoh untuk peralatan elektronik seperti laptop diperlukan tegangan DC 19-20V, sedangkan untuk handphone diperlukan tegangan DC $5 \mathrm{~V}$. Untuk itu di butuhkan suatu konverter yang dapat menjaga tegangan keluaran tetap pada level tertentu sesuai kebutuhan beban, walaupun tegangan masukan dan penggunaan daya berubahubah.

Selain itu isu mengenai saluran DC di rumahrumah yang disuplai oleh sumber energi terbarukan sudah ramai dibicarakan di forumforum internet, dan pada beberapa forum resmi oleh industri dan akademia. Dalam forum-forum tersebut, pertanyaan yang paling mendasar adalah berapa tegangan DC yang terbaik untuk distandardkan, dan bagaimana kesiapan seluruh produsen produk-produk elektrik dan elektronika untuk menyediakan terminal suplai DC pada produk mereka.

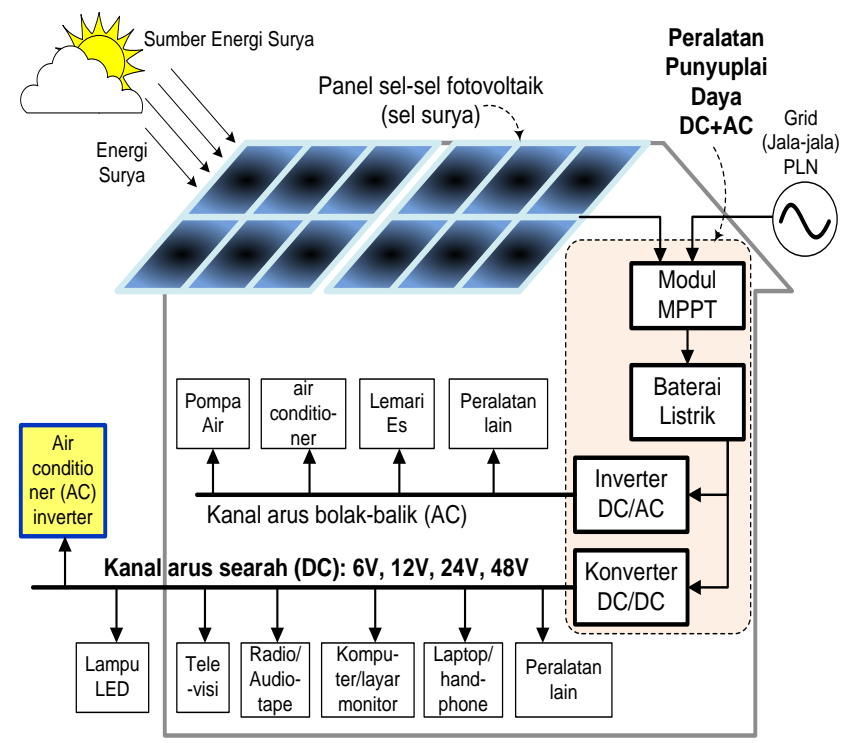

Gambar 1. Sistem listrik rumah tangga modern dengan saluran daya listrik DC dan AC

\section{Deskripsi Permasalahan}

Perubahan daya listrik langsung dari sumber energi terbarukan, maupun yang secara tidak langsung melalui baterai menyebabkan terganggunya suplai tegangan DC konstan yang diperlukan oleh beberapa peralatan-peralatan listrik DC rumah tangga. Perubahan beban juga memberikan andil terhadap perubahan tersebut. Selain itu, tidaknya adanya standard atas nilai tegangan DC, mendorong kebutuhan akan produk regulator tegangan yang keluaran tegangan DCnya dapat direkonfigurasi.

Paper ini akan menunjukkan rancangan konverter DC/DC [1,2] tipe buck menggunakan model SPICE dengan percobaan menggunakan kontrol P, PI, dan PD yang mampu secara fleksibel didesain untuk bekerja pada beberapa level tegangan DC. Agar dapat mensimulasikan rangkaiannya, maka model SPICE dari kendali P, PI, dan PD mesti diturunkan terlebih dahulu [3]. Percobaan menggunakan ketiga kontrol tersebut yaitu kontrol P, PI, dan PD dimaksudkan untuk mencari kontrol yang terbaik yang memberikan efisiensi daya yang signifikan.

\section{Hasil Perancangan}

Sistem Kendali PID telah banyak dan paling lazim digunakan untuk mengendalikan Konverter DC/DC [4, 5, 6, 7, 8]. Kontroler PID ini dapat direalisasikan secara analog atau pun secara digital [5]. Masalah paling mendasar dalam perancangan ini adalah bagaimana memilih parameter PID terbaik. Banyak metode yang dapat digunakan misalnya dengan teknik polinomial [6], teknik adaptif dikombinasikan dengan metode fuzzy logic [7], atau menggunakan teknik optimisasi khusus [8].

Paper ini akan mencoba mengkaji hasil rancangan dengan pendekatan simulasi PID analog menggunakan SPICE, dimana PID parameter akan dapat ditemukan melalui teknik eksplorasi simulasi parameter. Melalui teknik simulasi dengan variasi parameter ini, maka nilainilai PID terbaik dapat diestimasi. Ada dua kriteria yang digunakan dalam paper ini yaitu Nilai Average Absolute Error dan Efisiensi Daya dari setiap simulasi parameter nilai PID. Nilai konstanta kendali P, I dan D terbaik, tentu saja adalah yang memiliki nilai terkecil dari kedua kriteria tadi. 


\subsection{Pemodelan SPICE}

Perangkat keras yang akan dibangun didasarkan pada model rancangan. Contoh alur desain skematik rangkaian converter DC/DC tipe buck ditunjukkan pada Gambar 2.

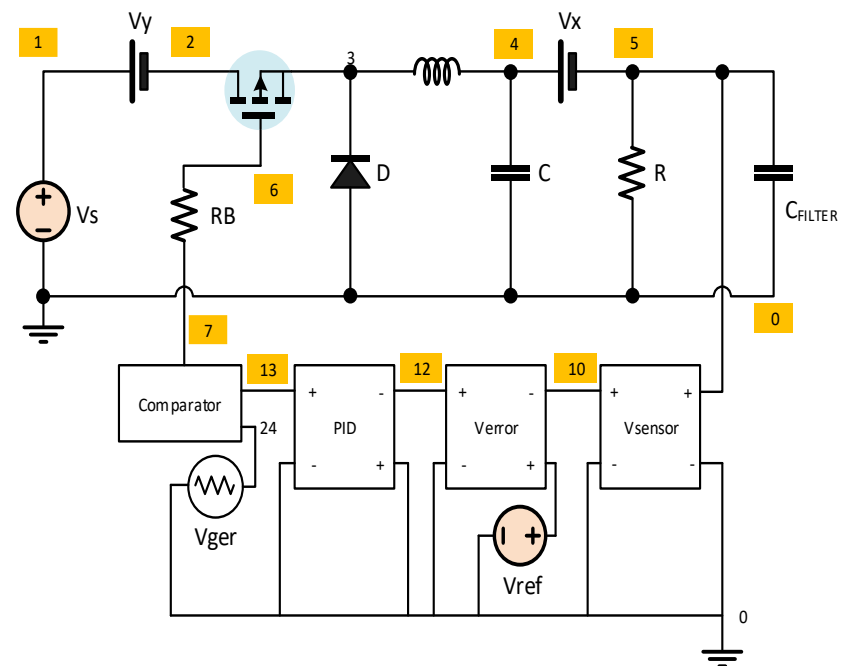

Gambar 2. Diagram kotak kontroler and skematika rangkaian converter DC/DC tipe buck.

\subsection{Perangkat Kendali PID}

Gambar 1 memperlihatkan skematik rangkain kendali PID. Kendali PID termodifikasi digunakan untuk mengendalikan level tegangan DC pada luaran konverter DC/DC. Selisih antara data sensor tegangan pada luaran konverter dan tegangan referensi Vref digunakan sebagai acuan untuk membangkitkan PWM.

\section{Hasil Simulasi}

Gambar 3 memperlihatkan pengukuran Average Absolute Error dan Efisiensi Daya dari hasil simulasi dengan hanya menggunakan kendali $\mathrm{P}$ dengan variasi nilai KP untuk tegangan 12V. Nampak terlihat bahwa nilai Average Absolute Error cenderung berubah ketika diberikan nilai KP yang bebeda. Hal yang sama juga terlihat pada Efisiensi Daya, bahwa nilai efisiensi cenderung meningkat pada nilai KP tertentu.

Gambar 4 memperlihatkan pengukuran Average Absolute Error dan Efisiensi Daya dari hasil simulasi menggunakan kendali PI dan dengan variasi nilai $\mathrm{K}_{\mathrm{I}}$ terhadap nilai $\mathrm{K}_{\mathrm{P}}$ untuk tegangan $12 \mathrm{~V}$. Nampak terlihat bahwa nilai Average Absolute Error cenderung berubah ketika diberikan nilai $\mathrm{K}_{\mathrm{I}}$ yang bebeda. Hal yang sama juga terlihat pada Efisiensi Daya, bahwa nilai efisiensi cenderung meningkat pada nilai $\mathrm{K}_{\mathrm{I}}$ dan $K_{P}$ tertentu. Sementara itu, perubahan nilai $K_{P}$ yang lebih besar cenderung menurunkan nilai pengukuran kedua parameter tadi.

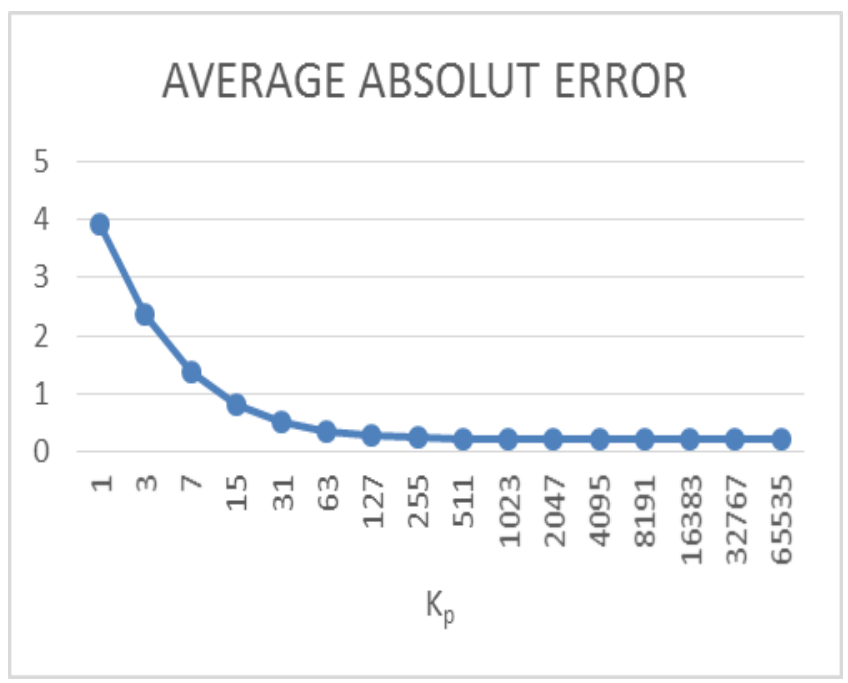

(a)

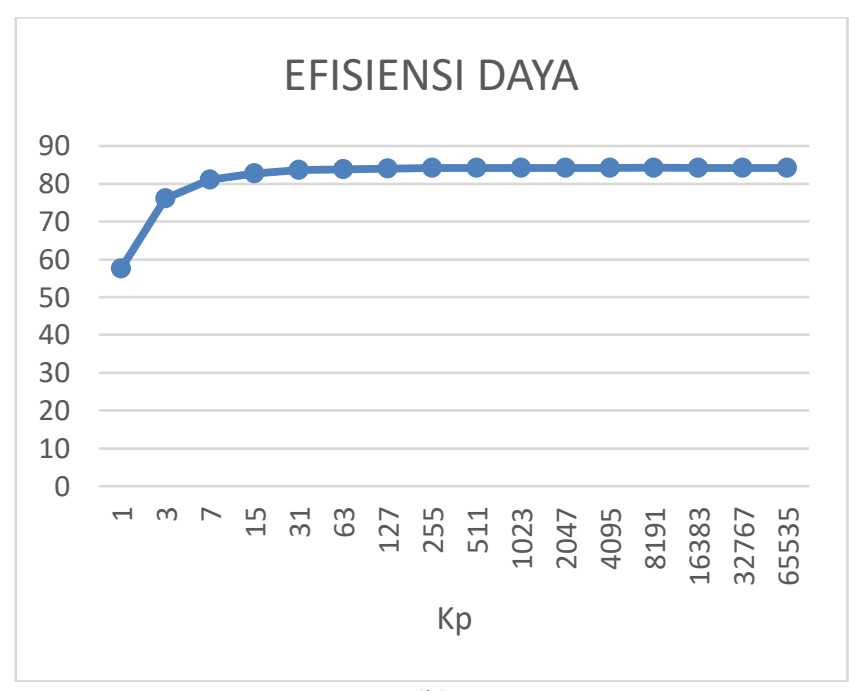

(b)

Gambar 3. (a) Average Absolut Error dan (b) Efisiensi Daya dari hasil simulasi menggunakan kendali $P$ yang nilainya bervariasi untuk tegangan input $12 \mathrm{~V}$ dan tegangan referensi $5 \mathrm{~V}$

Gambar 5 memperlihatkan pengukuran Average Absolute Error dan Efisiensi Daya dari hasil simulasi menggunakan kendali PD dan dengan variasi nilai $K_{D}$ terhadap nilai $K_{P}$ untuk tegangan $12 \mathrm{~V}$. Nampak terlihat bahwa nilai Average Absolute Error cenderung naik pada setiap kenaikan nilai $\mathrm{K}_{\mathrm{D}}$. Hal yang yang bervarisi terlihat pada Efisiensi Daya, bahwa nilai efisiensi 
cenderung meningkat pada nilai $\mathrm{K}_{P} \mathrm{~K}_{\mathrm{D}}$ tertentu, dan cenderung menurun pada $\mathrm{K}_{\mathrm{P}} \mathrm{K}_{\mathrm{D}}$ tertentu pula. Sementara itu, kecenderungan nilai Efisiensi Daya terendah terjadi pada $K_{P}$ yang semakin kecil.

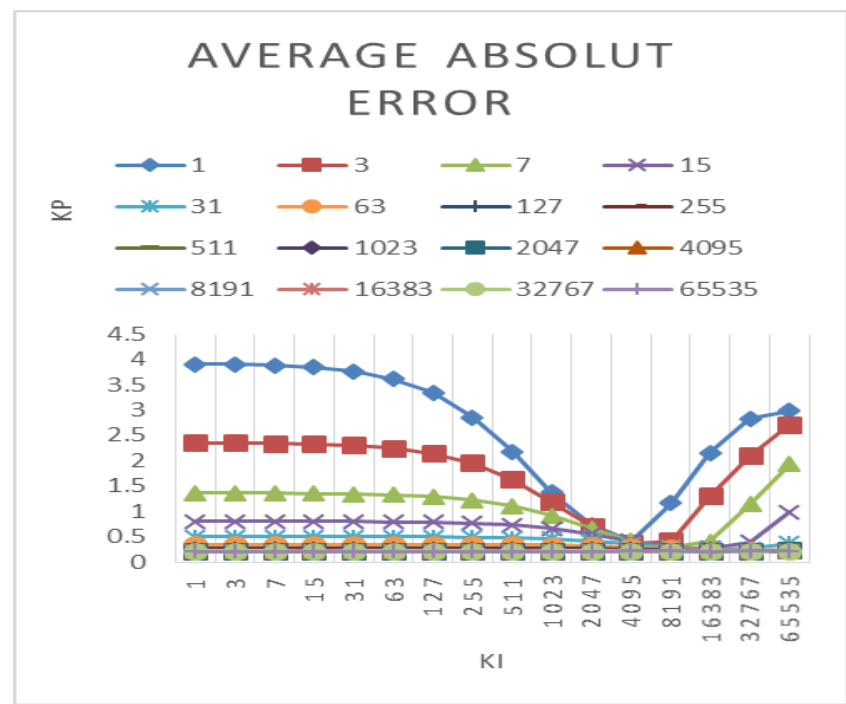

(a)

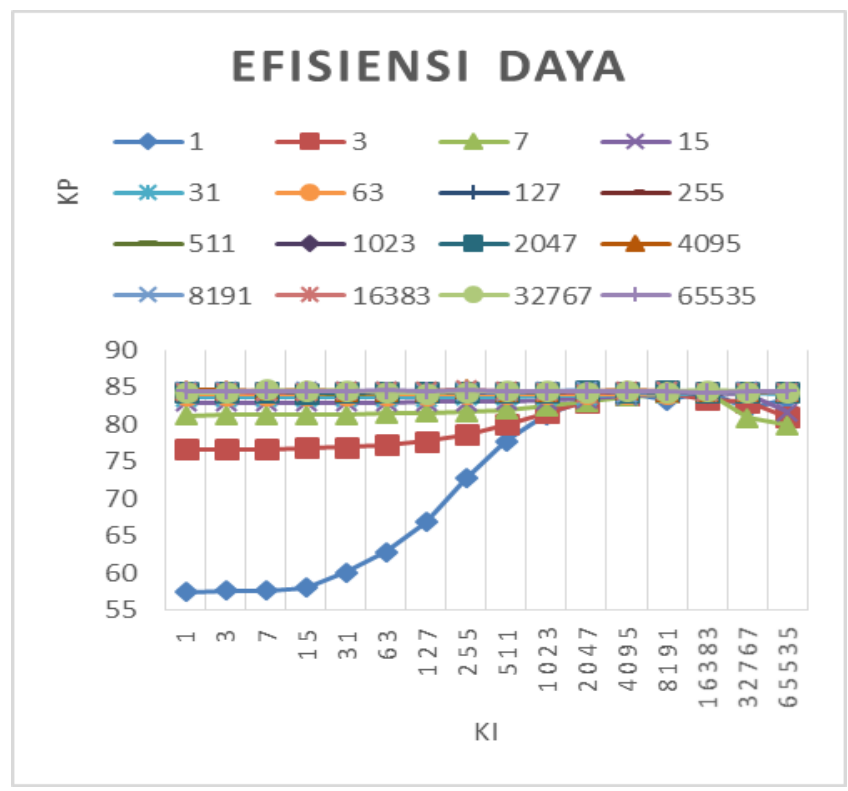

(b)

Gambar 4. (a) Average Absolut Error dan (b) Efisiensi Daya dari hasil simulasi menggunkan kendali P dan I yang nilainya bervariasi untuk tegangan input $12 \mathrm{~V}$ dan tegangan referensi $5 \mathrm{~V}$

Gambar 6 memperlihatkan hasil pengujian DC/DC Konverter tipe buck dengan kendali $\mathrm{P}$ dengan memberikan beban RL pada waktu $4 \mathrm{~ms}$ dan beban RC pada waktu $7 \mathrm{~ms}$. Nampak terlihat bahwa Konverter tipe buck dengan kendali $\mathrm{P}$ mampu mengendalikan level tengangan sesuai referensi untuk beban $\mathrm{RL}(100 \Omega, 20 \mathrm{~m})$, sedangkan untuk beban $\mathrm{RC}(10 \Omega, 2000 \mathrm{u})$ terlihat terjadi perubahan level tegangan, walaupun demikian kendali $\mathrm{P}$ dapat segera mengendalikan ke level yang sesuai dengan referensi yang diberikan.

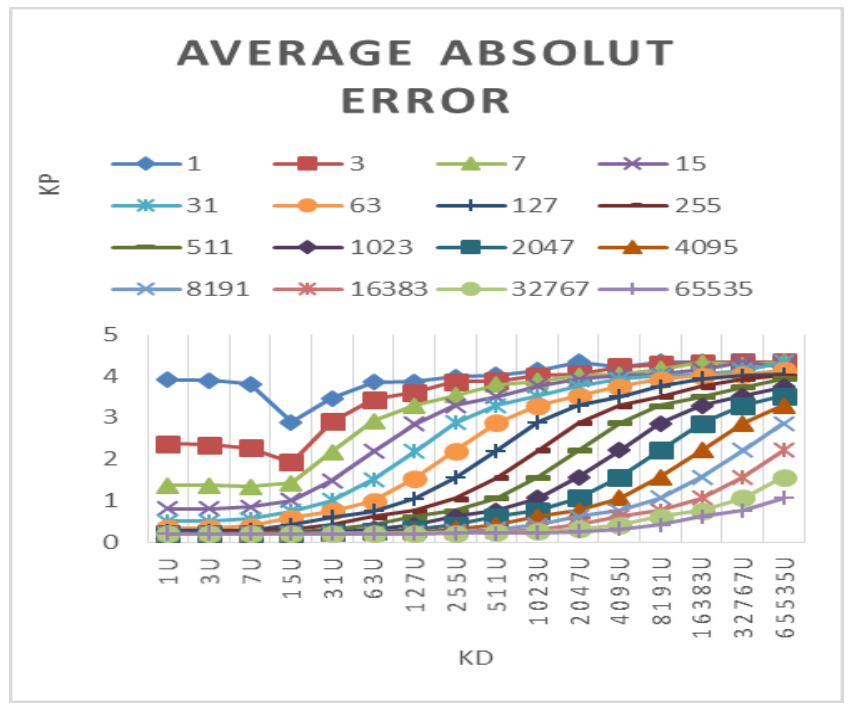

(a)

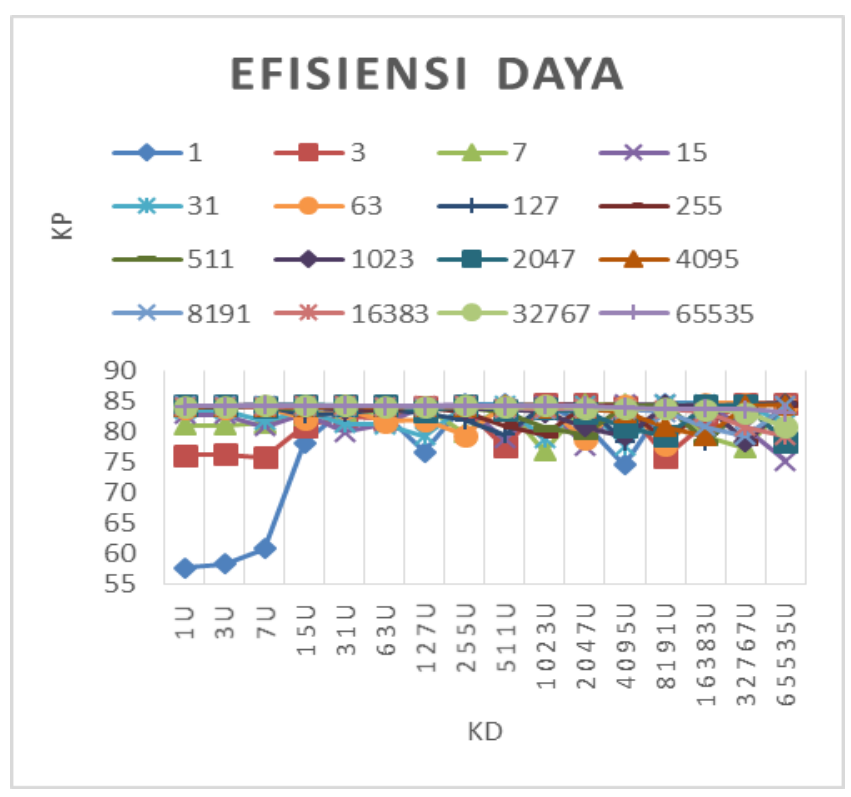

(b)

Gambar 5. (a) Average Absolut Error dan (b) Efisiensi Daya dari hasil simulasi menggunkan kendali P dan D yang nilainya bervariasi untuk tegangan input $12 \mathrm{~V}$ dan tegangan referensi $5 \mathrm{~V}$

Gambar 7 memperlihatkan hasil pengujian DC/DC Konverter tipe buck dengan kendali PI dengan memberikan beban RL pada waktu $4 \mathrm{~ms}$ dan beban RC pada waktu $7 \mathrm{~ms}$. Nampak terlihat bahwa Konverter tipe buck dengan kendali PI 
mampu mengendalikan level tengangan sesuai referensi untuk beban $\mathrm{RL}(100 \Omega, 20 \mathrm{~m})$, sedangkan untuk beban RC $(10 \Omega, 2000 \mathrm{u})$ terlihat terjadi perubahan level tegangan, walaupun demikian kendali PI dapat segera mengendalikan ke level yang sesuai dengan referensi yang diberikan.

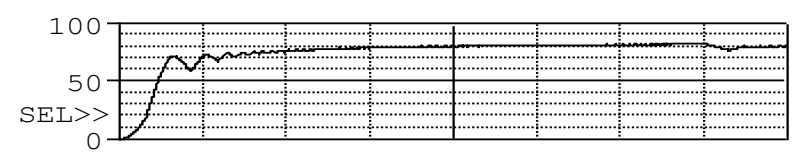

$\left(\operatorname{avg}\left(I\left(V_{X}\right) \star_{V}(5)\right) / \operatorname{avg}\left(I\left(V_{Y}\right) \star_{V}(1)\right)\right){ }^{\prime} 100$

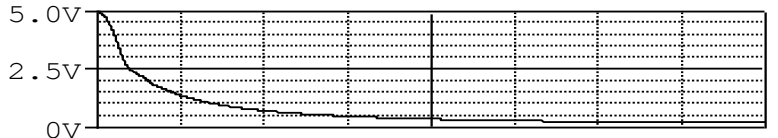
ㅁ $\operatorname{AVG}(\operatorname{ABS}(V(12)))$
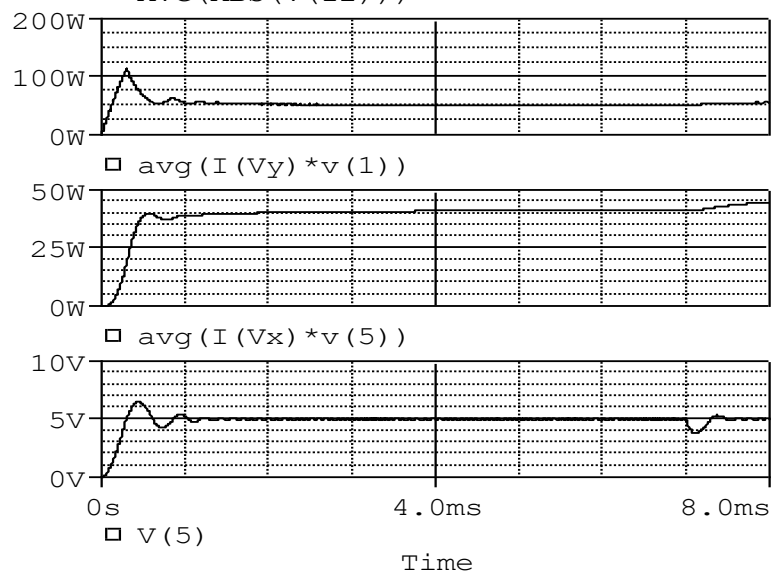

Gambar 6. Pengujian kendali $P$ terhadap beban RL(4ms) RC(7ms) untuk tegangan input $12 \mathrm{~V}$ dan tegangan referensi $5 \mathrm{~V}$

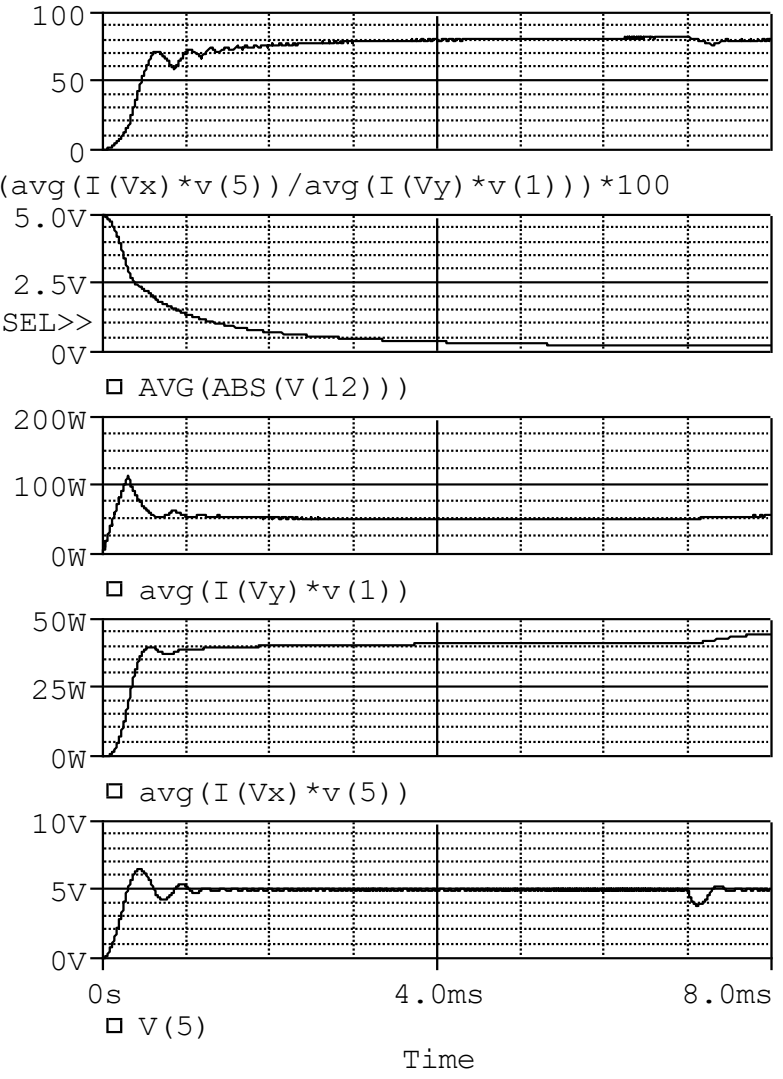

Gambar 7. Pengujian kendali PI terhadap beban RL(4ms) RC(7ms) untuk tegangan input $12 \mathrm{~V}$ dan tegangan referensi $5 \mathrm{~V}$

Gambar 8 memperlihatkan hasil pengujian DC/DC Konverter tipe buck dengan kendali PD dengan memberikan beban RL pada waktu $4 \mathrm{~ms}$ dan beban RC pada waktu $7 \mathrm{~ms}$. Nampak terlihat bahwa Konverter tipe buck dengan kendali PD mampu mengendalikan level tengangan sesuai referensi untuk beban $\operatorname{RL}(100 \Omega, 20 \mathrm{~m})$, sedangkan untuk beban $\mathrm{RC}(10 \Omega, 2000 \mathrm{u})$ terlihat terjadi perubahan level tegangan, walaupun demikian kendali PD dapat segera mengendalikan ke level yang sesuai dengan referensi yang diberikan. 


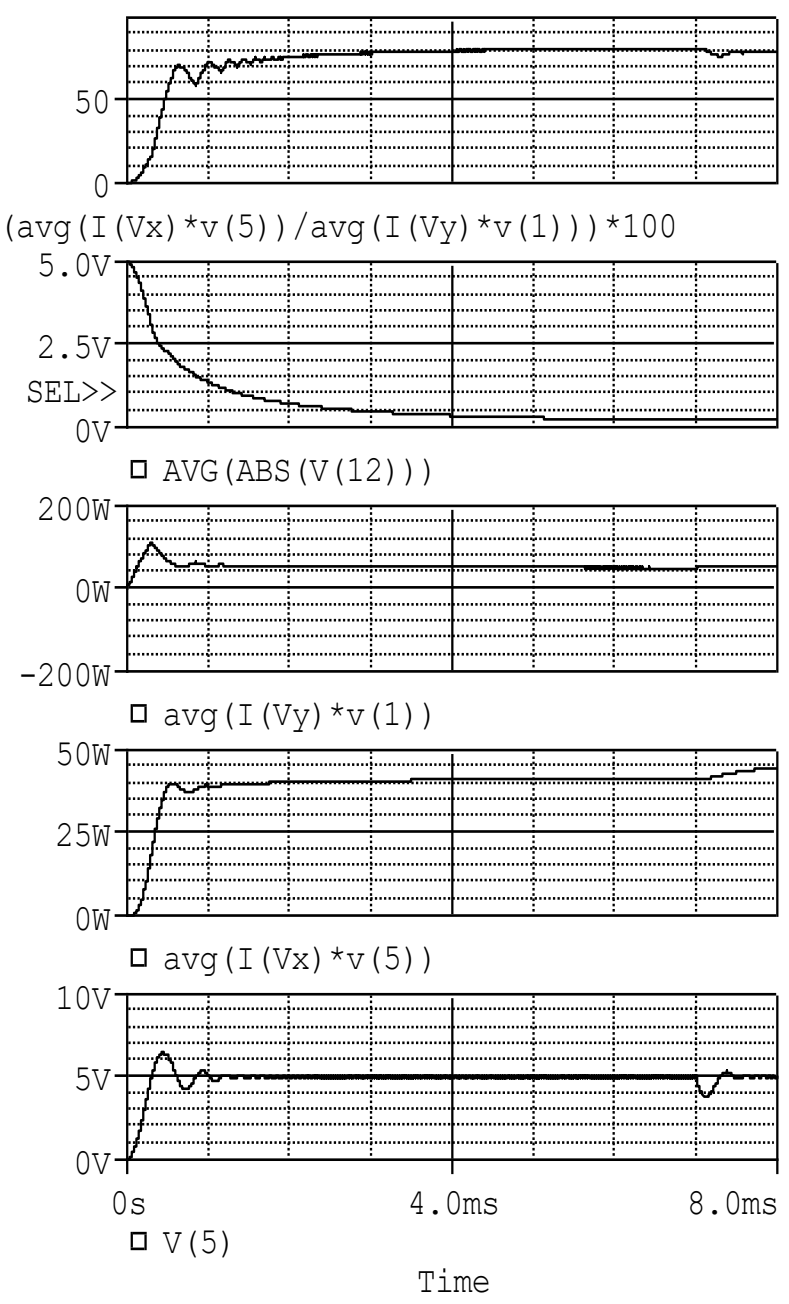

Gambar 8. Pengujian kendali PD terhadap beban RL(4ms) RC(7ms) untuk tegangan input $12 \mathrm{~V}$ dan tegangan referensi $5 \mathrm{~V}$

\section{Kesimpulan}

Pencobaan simulasi kendali P, PI, PD pada Konverter tipe Buck dengan domain isyarat kesalahan yang dibatasi telah ditunjukkan pada paper ini. Hasil rancangan menunjukkan kendali P, PI, PD yang digunakan untuk mempertahankan tegangan luaran DC dari converter telah memberikan kinerja yang cukup baik. Walaupun antara menggunakan kendali P, PI, dan PD tidak memiliki perbedaan yang sangat signifikan terhadap pengendalian pada beban RL dan RC.

Penggunaan penggabungan kendali PI dan PD terlihat mampu meningkatkan nilai Efisiensi Daya yang disalurkan dari pada hanya menggunakan kendali P saja. Nilai Efisiensi yang didapatkan PI yaitu 84.72 dan PD yaitu 84.616. Sedangkan dengan hanya menggunakan kendali $\mathrm{P}$ nilai efisinsi terbaik yang didapatkan yaitu 84.283.

Nilai-nilai paramater pengendali terbaik yang diperoleh untuk tegangan Input $12 \mathrm{~V}$ dan Referensi 5V antara lain $\mathrm{KP}=8191, \mathrm{KI}=63$, dan $\mathrm{KD}=7 \times 10^{-6}$ merupakan contoh-contoh nilai yang dapat digunakan sebagai acuan untuk dua buah kriteria yang telah digunakan yaitu minimisasi Average Absolute Error dan meningkatkan Efisiensi Daya. Penggunaan tegangan Input dan Referensi yang lain tentunya membutuhkan nilainilai konstanta kendali PID yang bebeda pula. Oleh karena itu, kajian lebih lanjut mengenai pemilihan nilai-nilai parameter dan multi kriteria yang berbeda-beda masih terus kami lakukan.

\section{Referensi}

[1] Muhammad H. Rashid. "Power Electronics Handbook Third Edition". University of West Florida.

[2] Mohan, Ned, Undeland, T.M., and Robbins, P. W., "Power Electronics Converters Applications and Design", Second Edition, John Wiley and Sons.

[3] Muhammad H. Rashid, Hasan M. Rashid, "SPICE for Power Electronics And Electric Power Second Edition". University of West Florida. Taylor \& Francis CRC.ISBN 0-8493-3418-7.

[4] Chao-Ying Wang. 2015, "A Voltage-Mode DC-DC Buck Converter with Digital PID Controller". 12th International Conference on Fuzzy Systems and Knowledge Discovery (FSKD). Electronic ISBN: 9781-4673-7682-2.

[5] Zhou Chu. 2014. "A general digital PID controller based on PWM for buck converter". IEEE World Congress on Intelligent Control and Automation (WCICA), Page(s):4596-4599.

[6] MadhuKiran, E.R.C.S. 2012. "Control of Buck converter by Polynomial, PID and PD controllers". IEEE Asia Pacific Conference on Postgraduate Research in Microelectronics and Electronics (PrimeAsia). Page(s): 94-99.

[7] Rabbani, M. 2012. "Fuzzy logic driven adaptive PID controller for PWM based buck converter". IEEE International Conference on Informatics, Electronics \& Vision (ICIEV). Page(s): 985-962.

[8] Sridhar Seshagiri, 2016, "Optimal PID Design for Voltage Mode Control of DC-DC Buck Converters" 2016 IEEE 13th International Conference on Networking, Sensing, and Control (ICNSC). Electronic ISBN: 978-1-4673-9975-3. 